\title{
Late onset anaemia in Rhesus haemolytic disease of the newborn
}

\author{
*Chandima Roshani Gunaratne ${ }^{1}$, Thusitha Sameera Kumarasiri ${ }^{2}$
}

Sri Lanka Journal of Child Health, 2022; 51(1): 149-151

DOI: http://dx.doi.org/10.4038/sljch.v51i1.10025

(Key words: Rhesus isoimmunisation, Haemolytic disease of newborn, Late anaemia)

\section{Introduction}

Haemolytic disease of the newborn secondary to Rhesus isoimmunisation ( $\mathrm{Rh} \mathrm{HDN}$ ), is a preventable disease caused by the transplacental transfer of maternal erythrocyte IgG alloantibodies, active against paternal $\mathrm{Rh}$ antigens on the fetal red blood cells (RBC), leading to increased fetal and neonatal RBC destruction ${ }^{1-5}$. These antibodies are generated by exposure of fetal blood into the maternal circulation, resulting from feto-maternal haemorrhage secondary to a previous pregnancy, abortion, trauma or invasive procedure ${ }^{1}$. This phenomenon, called sensitization / isoimmunisation, is common during the first pregnancy and reduced during subsequent pregnancies ${ }^{1}$.

Incidence of $\mathrm{Rh} \mathrm{HDN}$ is declining, owing to the introduction of anti-D immune-prophylaxis since $1968^{4,5}$. However, despite adequate immuneprophylaxis, 1-3 in $1000 \mathrm{Rh}$ D negative women still develop Anti-D antibodies ${ }^{5}$. Postnatal care of Rh HDN consists of phototherapy and exchange transfusion to treat hyperbilirubinaemia and RBC transfusions to treat early and late anaemia respectively ${ }^{5}$. Clinical manifestations of Rh HDN vary in severity from asymptomatic to hydrops fetalis and/or stillbirth associated with severe anaemia in utero to anaemia of variable severity after birth with or without jaundice ${ }^{1-5}$. Rarely, babies with mild or no symptoms at birth may present later with severe haemolytic anaemia, which is an uncommon yet well-recognized presentation of $\mathrm{Rh}$ $\mathrm{HDN}^{1,2}$.

${ }^{1}$ Acting Consultant Neonatologist, Teaching Hospital, Batticaloa, Sri Lanka, ${ }^{2}$ Senior Registrar in Emergency Medicine, National Hospital of Sri Lanka

*Correspondence: mail2roshii@yahoo.com

iD,

https//orcid.org/ 0000-0002-0798-1986

(Received on 20 February 2021: Accepted after revision on 23 April 2021)

The authors declare that there are no conflicts of interest

Personal funding was used for the project.

Open Access Article published under the Creative

Commons Attribution CC-BY (c) (i) License

\section{Case report}

A 29-year-old O negative mother delivered a term baby girl by lower segment caesarean section due to delayed second stage of labour. This was the second baby of non-consanguineous parents and weighed $3 \mathrm{~kg}$ at birth. Mother's first pregnancy and past medical history were uncomplicated, and Anti-D immunoglobulin was administered within 72 hours following a normal vaginal delivery as the baby's blood group was $\mathrm{O}$ positive.

Her Anti-D antibody levels were not checked during this pregnancy as she had defaulted antenatal clinic follow up. Following delivery, cord blood reports showed a total bilirubin level (TBL) of $67.9 \mu \mathrm{mol} / \mathrm{L}$ which is well below phototherapy level and a haemoglobin $(\mathrm{Hb})$ level of $16.4 \mathrm{~g} / \mathrm{dl}$ with a reticulocyte count (RC) of $6.3 \%$, which are in the high normal range (normal range in newborns 3$7 \%$ ). Baby's blood picture showed evidence of haemolysis. Direct Coombs test (DAT) was strongly positive. After consulting the transfusion physician, extended immune-phenotyping of the baby's blood was performed and the group was stated as $\mathrm{O}$ and the Rh status was to be confirmed at the age of 4 months owing to the presence of a significant number of allo-antibodies in the baby's blood.

Serial TBL levels were done. TBL on day 2 of life was at the phototherapy level, while all other serial TBLs were well below the phototherapy level. However, the baby was given single phototherapy as a prophylactic measure. Table 1 gives a summary of the investigations.

On day15, baby developed severe pallor with a $\mathrm{Hb}$ of $4.9 \mathrm{~g} / \mathrm{dL}$, a very high RC of $22.1 \%$ along with a blood picture showing severe haemolysis, suggestive of late anaemia following rhesus isoimmunisation. As recommended by the transfusion physician, two $10 \mathrm{ml} / \mathrm{kg}$ of top-up packed red cell transfusions were given. A double volume exchange transfusion was done to correct anaemia alongside removal of sensitized immunoglobulins in baby's blood to halt the ongoing severe haemolysis. On day 20 of life, her total blood count showed a $\mathrm{Hb}$ level of $13.4 \mathrm{~g} / \mathrm{dl}$, a RC of $1.6 \%$ along with no active haemolysis in the blood picture. The baby was discharged on day 21 on folic acid $1 \mathrm{mg}$ daily. Regular clinic follow-up was arranged. 


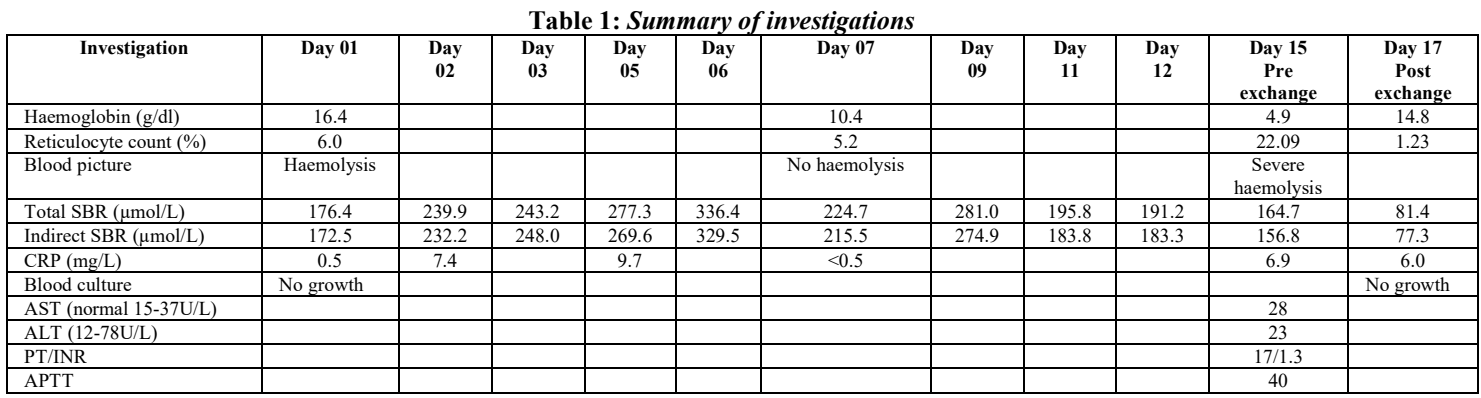

SBR-serum bilirubin, CRP-C reactive protein, AST-Aspartate aminotransferase, ALT-alanine aminotransferase, PT-prothrombin time, INRinternational normalization ratio, APTT-activated partial thromboplastin time

\section{Discussion}

Maternal allo-immunization can be triggered by more than 50 different erythrocyte antigens, but most severe cases involve the Rhesus-D antigen (Rh $D)^{5}$. In the majority of mothers, sensitization occurs during labour; hence, sensitization usually does not affect the first-born baby but subsequent babies, which is evident in our case ${ }^{1}$. Isoimmunisation can be prevented by the administration of prophylactic doses of anti-D immunoglobulin during 28 weeks and 34 weeks of pregnancy a well as within 72 hours of delivery to neutralize the effect of paternally derived $\mathrm{Rh} \mathrm{D}$ antigens entering the maternal blood $^{1,4}$. However, anti-D therapy may not prevent all cases of isoimmunisation ${ }^{1,4}$.

Postnatal anaemia in Rh HDN is divided into early anaemia due to excessive haemolysis (occurs up to day 7), and late anaemia, as is the case in our baby, which can occur in $83 \%$ of neonates of gestational age $\geq 35$ weeks, manifesting up to 3 months of life, due to the continuous destruction of baby's RBCs by persistent iso-antibodies in neonatal circulation for 6-10 weeks ${ }^{1,2,4,5}$.

Benign early neonatal course of the disease will not necessarily reflect the severity of Rh HDN, including the occurrence of late anaemia, providing false reassurance with normal cord haemoglobin and subsequent $\mathrm{Hb}$ values in the early neonatal period ${ }^{2}$. Improved reticulo-endothelial function during the second week of life is the proposed mechanism for this remarkable phenomenon of increased rate of erythrocyte destruction after the 1 st week of life, leading to severe haemolytic anemia with mild or no haemolysis at birth ${ }^{1,2,4,5}$. Moreover, owing to the parallel maturation of hepatic function with an increasing capacity for bilirubin conjugation and excretion, increased rate of haemolysis is not always accompanied by a significant rise in serum bilirubin ${ }^{1,2,4,5}$. Our baby had a similar natural course.

Late onset anaemia is common in babies with $\mathrm{Rh}$ isoimmunisation who had not received an exchange transfusion during the immediate post-natal period, as it increases the clearance of bilirubin, remove alloantibodies and treats anaemia, as neonatal blood is replaced by immunologically compatible donor blood $^{4,5}$.

Primary treatment of anaemia of Rh HDN is administration of erythrocyte transfusions known as top-up transfusions, with the mean age of $1^{\text {st }}$ transfusion 18 days (range 1-34 days), needing further transfusions till late anaemia resolves by 3 months of life ${ }^{5}$. At least one top-up transfusion is reported to be required in $68-83 \%$ of neonates with $\mathrm{Rh}$ HDN and some needed up to 6 top up transfusions in the first 3 months of life 5 . Rate of top-up transfusions is significantly higher in neonates in whom early exchange transfusion was not performed and in newborns treated with intrauterine transfusions ${ }^{5}$.

Other pharmaco-therapeutic options such as recombinant human erythropoietin and folate supplements, need further research to ascertain their usefulness in managing $\mathrm{Rh}_{\mathrm{HDN}^{5}}$.

This case indicates that all infants with Rh HDN should be considered at risk for late anaemia, even in the absence of jaundice / anaemia during the immediate postnatal period; therefore, post discharge surveillance with periodic examinations and repeat measurements of haemoglobin levels are necessary ${ }^{1,2}$.

\section{References}

1. Haider M, Memon S, Tariq F, Fatima S, Hameed A. Rhesus isoimmunisation: late onset hemolytic disease of the newborn without jaundice. Cureus 2020; 12(1): e6559.

https://doi.org/10.7759/cureus.6559

2. Mitchell S, James A. Severe late anaemia of haemolytic disease of the newborn. Paediatrics and Child Health 1999; 4(3): 201-3. https://doi.org/10.1093/pch/4.3.201 PMid: 20212966 PMCid: PMC2828194 
3. Urbaniak SJ, Greiss MA. RhD haemolyitc disease of the fetus and the newborn. Blood Reviews 2000; 14(1): 44-61.

https://doi.org/10.1054/blre.1999.0123

PMid: 10805260

4. Jadala HV, Pooja V, Raghavendra K, Prithvish CM, Srinivas B. Late onset severe anemia due to rhesus isoimmunization. International Journal of Contemporary Pediatrics 2016; 3(4): 1472-3.

https://doi.org/10.18203/23493291.ijcp20

163704
5. Ree IMC, Smiys-Wintjens VEHJ, van der Born JG, van Klink JMM, Oepkes D, Lopriore E. Neonatal management and outcome in alloimmune haemolytic disease. Expert Review of Hematology 2017; 10(7): 607-16.

https://doi.org/10.1080/17474086.2017.13 31124

PMid: 28503958 